\title{
PICTURE OF THE MONTH
}

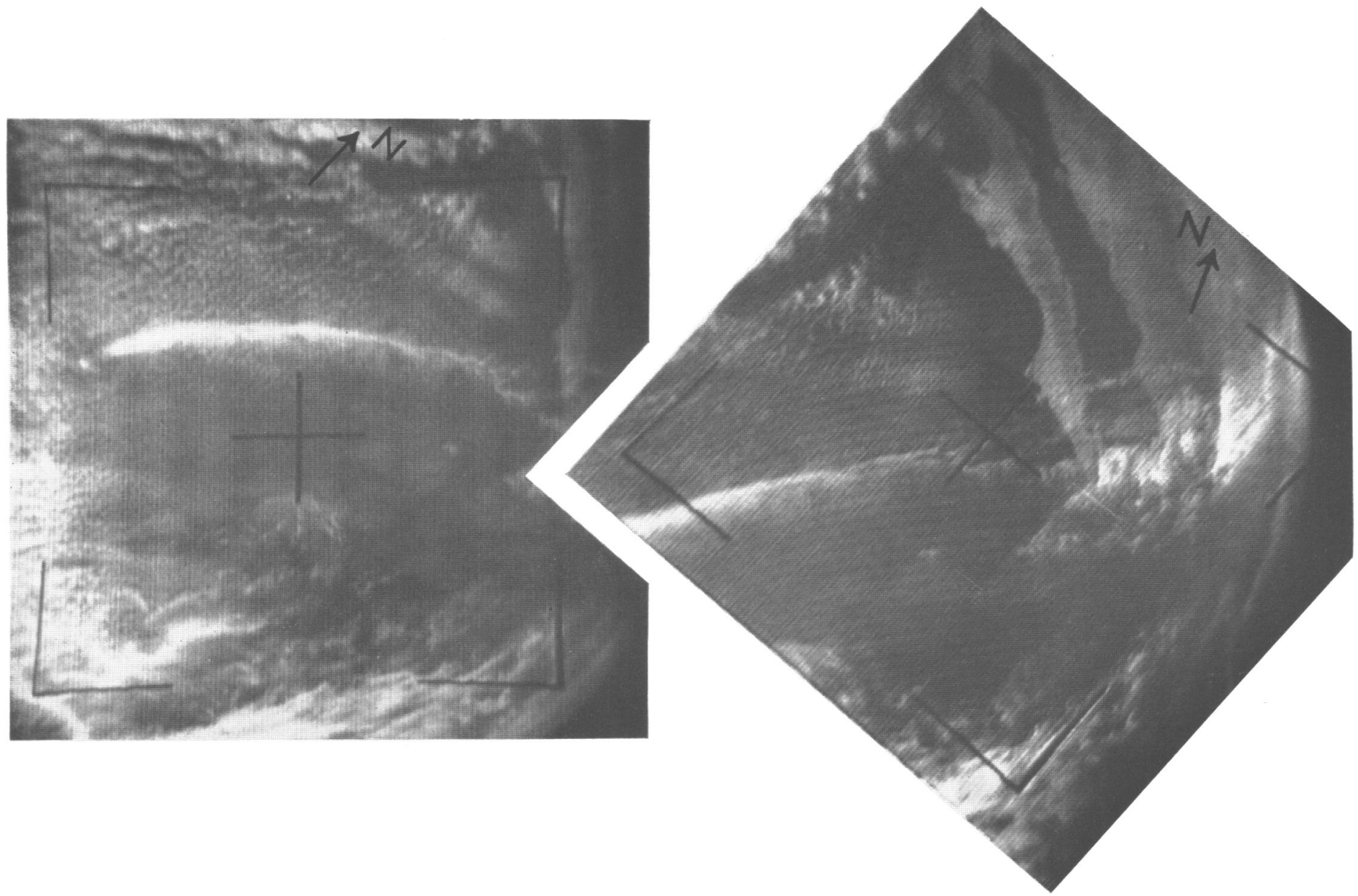

These two TIROS V photographs (pass 4363/4362, camera 1, frames 28 and 26) were taken on April 19, 1963, at approximately 1917 GMT and were received at Point Mugu, Calif., via tape mode. Baja California is clearly visible in the photograph at right, and it also appears in the upper right corner of the picture at left. North is indicated by the arrows.

A striking and unexplained feature is the long streak of cloud oriented approximately WSW-ENE across the middle of both pictures. The western end of the cloud streak is located near a small bright cloud which is about $500 \mathrm{mi}$. southwest of Baja California, and the streak itself extends in an unbroken line nearly to the southern end of that peninsula. Broken and less well defined filaments continue across the peninsula and well into the mainland of Mexico. A somewhat similar cloud feature, occurring in the same general area, appeared as the April 1963 "Picture of the Month."

The cloud streak and the associated filaments almost certainly are composed of cirrus or cirriform clouds at a much higher elevation than the low-level stratocumulus present beneath the streak and to the north of it. At least three possible explanations may be offered, none of which seems entirely satisfactory:

(1) The cirrus streak was produced by upward motion in the high troposphere associated with a nearby jet stream;

(2) The small bright cloud near' the western end of the streak is a cumulonimbus cloud that produced the long plume of cirrus;

(3) The cirrus plume is the outgrowth of an aircraft condensation trail. 